\section{The borrowers afield}

\section{Peter J. Bowler}

Darwinian Evolution.

By Antony Flew.

Paladin: 1984. Pp. 149. Pbk $£ 2.50$.

THE prospectus for Paladin's Movements and Ideas series openly challenges Fontana's Modern Masters and Oxford University Press's Past Masters, arguing that major intellectual movements cannot adequately be described through the medium of biography. Antony Flew's Darwinian Evolution, one of the early volumes in the series, is thus meant to supplant the accounts of Darwin's work by Wilma George (Fontana) and Jonathan Howard (Oxford).* The three books have a similar format - all are slim paperbacks with peculiar covers - but their purposes are indeed rather different. Of the two earlier accounts, George's is more sympathetic to the cultural environment in which Darwinism developed, and makes an effort to relate the theory to wider debates. Flew's real interest is the latter area. He summarizes Darwin's career and the argument of the Origin of Species, but the substance of the book is its analysis of the philosophical and ideological issues.

It is perhaps inevitable that so brief a study should concentrate on the areas with which the author is most familiar, but some readers may find the choice of topics unbalanced. Flew's purpose is to uncover the logical core of Darwinism and then show how that core fails to support many of the ideological systems that have used it as a foundation. He explores the logical structure of the theory of natural selection, and refutes at length the claim that the theory rests on a tautology. In the process, the cladists at the Natural History Museum are dismissed as Aristotelians. But we are told virtually nothing about taxonomy, biogeography, speciation and other topics of primary importance to Darwin and all later Darwinians. The structure of the theory is obviously important, but I doubt that a newcomer to the field can be given an adequate impression of what scientific Darwinism is all about by concentrating so narrowly on this topic.

On the ideological front, Flew discusses the influence of Malthus and Adam Smith at some length. He defends Malthus against the criticisms of Marx and other social reformers by stressing the deductive character of the principle of population. Curiously, the movement to defend laissezfaire capitalism as an extension of Darwinian principles is passed over in a couple of pages, and Herbert Spencer receives scarcely a mention. Flew's energy is conserved for an assault on the Marxists, whose links with Darwinism are systematically demolished. His arguments are

\footnotetext{
* Reviewed together in Nature 296, 510 (1982).
}

valid, but the section degenerates into a wholesale critique of Marxism which seems out of place in a book supposedly devoted to Darwinism. Flew also attacks Desmond Morris and those who would reduce human beings to animals, but defends sociobiology against intolerant radicals by pointing out that it is not meant to explain all human behaviour.

Flew's efforts to expose the weak links in the ideological connections are stimulating contributions to a number of debates, but

\section{Price changes}

\section{Michael F. Claridge}

Insect Ecology, 2nd Edn.

By Peter W. Price.

Wiley: 1984. Pp. 607. \$47.50, £37.50.

THE second edition of Peter Price's Insect Ecology, the first of which was published in 1975 , is far more than an up-dated and corrected reprint. Undoubtedly the most significant feature of the first edition was the stress placed upon the evolutionary aspects of the subject. This emphasis is retained, but thorough revision has produced a more balanced text. The book deals with the fundamental problems of ecology as exemplified by terrestrial ecosystems. Such ecosystems are mostly dominated numerically by green plants and insects, but while the author is thus able to consider all of the major aspects of terrestrial ecology by reference to these organisms, he frequently uses examples from other taxa and habitat types when they are relevant to his main theme.

The introductory chapters provide a brief but excellent account of the principal components and the functioning of ecosystems. A new chapter is included on the very important ecological consequences resulting from the relatively small sizes of insects. Most of the remainder of the book consists of chapters under three general headings - "Trophic Relationships", "Populations" and "Communities and Distributions" - which develop in a more logical and satisfying manner than in the first edition. There are useful accounts of insect-plant, predator-prey and parasitehost interactions, while elsewhere Price argues persuasively for the importance of mutualistic interactions which he justifiably claims have been sadly neglected until recently by ecologists. He also provides a stimulating and thoughtprovoking discussion of the possible evolutionary consequences of different types of interspecific interactions.

The chapters concerned with population processes have been extended, and in themselves constitute a helpful text for students. The final section, on community ecology, includes lucid accounts of some current areas of ecological controversy, such as the role of competition in the structuring of in a series entitled Movements and Ideas one might have expected a more historical approach. The various forms of social Darwinism may be perversions of the scientific theory, but we need to know why so many political movements have tried to link themselves with Darwin's name.

Peter J. Bowler is a Lecturer in History and Philosophy of Science at the Queen's University of Belfast. He is the author of Evolution: the History of an Idea (1984).

communities and the relationships between diversity and stability.

For this new edition the original material has obviously been reworked in detail. In most areas this has led to a clearer and better book. For example, a whole chapter was previously devoted to "species packing"; now the term does not even appear in the index, and the phenomena are dealt with more objectively under the niche and related concepts. Rightly so - ecology does not need redundant terminology!

The book is well written, as before, and is illustrated with many new and beautiful line drawings. In its new, improved form, Insect Ecology will continue to be the place to start for advanced students of the subject.

Michael F. Claridge is Professor of Entomology in the Department of Zoology at University College, Cardiff.

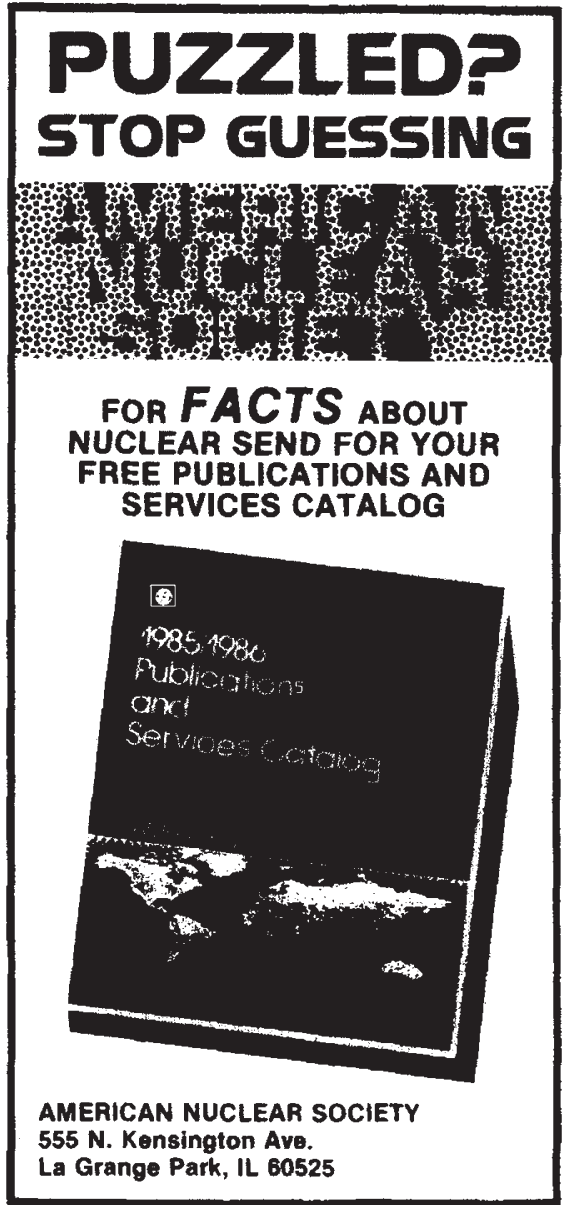

